\title{
Dampak Kebijakan Menteri Agama Terhadap Pembinaan Penyuluh Keagamaan: Kasus Di Kecamatan Talaga Raya Kabupaten Buton Tengah
}

\author{
Akhmad Sukardi ${ }^{1}$, Mansur ${ }^{2}$ \\ ${ }^{1}$ Fakultas Ushuluddin, Adab dan Dakwah, IAIN Kendari \\ ${ }^{2}$ Fakultas Ushuluddin, Adab dan Dakwah, IAIN Kendari \\ e-mail: akhmadsukardi.iainkendari@gmail.com , mansur@iainkendari.ac.id
}

\begin{abstract}
This study focuses on describing the recruitment system of religious instructors, especially Islamic religious instructors in Talaga Raya District, Central Buton Regency, based on the policy of the Ministry of Religion of the Republic of Indonesia number. DJ.III/432 of 2016 through the Director General of Islamic Community Guidance, and the Impact of the recruitment system policy of non-civil servant extension workers based on the policy of the Ministry of Religion of Republic of Indonesia number DJ.III/432 of 2016. The focus of the study traces the impact of the Ministry of Religion of the Republic of Indonesia on the recruitment pattern non-civil servant religious educators on the performance of instructors in the community of Talaga Raya District. By using the case study approach. The results showed that the mechanism of recruitment of non-civil servant religious counselors in Talaga Raya sub-district of Central Buton was not found to be any deviation in the sense of walking according to technical instructions for the appointment of non-civil servant Islamic religion instructors. The impact of the religious extension system recruitment system policy is twofold, namely (1) The performance of non-civil servant Islamic religion instructors is not maximal because the recruits do not have counseling competencies, the recruits do not match the educational background as extension agents. In addition, the low incentive of honorary counselors makes the performance of instructors not optimal. (2) Turn off some of the Qur'an Education Parks because the recruitment of religious instructors is not village-based so that some villages do not have extension workers. The promotion of religious instructors is not effective because the ratio of instructors to the target groups is not balanced.
\end{abstract}

Keywords: Recruitment System, Islamic Instructor. 


\begin{abstract}
Abstrak
Penelitian ini fokus mendeskripsikan sistem rekruitmen penyuluh keagamaan khususnya penyuluh agama Islam di Kecamatan Talaga Raya Kabupaten Buton Tengah, berdasarkan kebijakan Kementerian Agama Republik Indonesia nomor. DJ.III/432 Tahun 2016 melalui Direktur Jenderal Bimbingan Masyarakat Islam dan Dampak kebijakan sistem rekruitmen tenaga penyuluh non PNS berdasarkan kebijakan Kementerian Agama RI nomor DJ.III/432 Tahun 2016. Fokus penelitian menelusuri tentang dampak Kebijakan Kementerian agama Republik Indonesia terhadap pola rekruitmen penyuluh keagamaan non PNS terhadap kinerja para penyuluh pada masyarakat Kecamatan Talaga Raya. Dengan menggunakan metode pendekatan studi kasus. Hasil penelitian menunjukkan bahwa mekanisme rekruitmen penyuluh agama non PNS di kecamatan Talaga Raya Kabupaten Buton Tengah tidak ditemukan adanya penyimpangan dalam arti berjalan sesuai petunjuk teknis pengangkatan penyuluh agama Islam non PNS. Dampak kebijakan system rekruitmen penyuluh agama ada dua yaitu (1) Kinerja Penyuluh agama Islam non PNS tidak maksimal penyebabnya adalah tenaga yang direkrut tidak memiliki kompetensi kepenyuluhan, tenaga yang direkrut tidak sesuai latar belakang pendidikan sebagai penyuluh. Selain itu, rendahnya insentif para penyuluh honorer menjadikan kinerja para penyuluh tidak maksimal. (2) Mematikan Beberapa Taman Pendidikan Alquran karena perekrutan penyuluh agama tidak berbasis desa sehingga sebahagian desa tidak memiliki tenaga penyuluh. Pembinaan penyuluh agama tidak efektif karena rasio penyuluh dengan kelompok binaannya tidak seimbang.
\end{abstract}

Kata kunci: Sistem Rekrutmen, Penyuluh Agama Islam.

\title{
A. Pendahuluan
}

Salah satu ujung tombak Kementerian Agama Republik Indonesia dalam pembinaan dan pengembangan pemahaman keagamaan (agama Islam) bagi masyarakat adalah keberadaan tenaga penyuluh agama Islam di tengah-tengah masyarakat. Dengan mengemban tugas sebagai penyuluh agama, diharapkan kehadiran mereka di desa-desa menjadi "problem solver" bagi masyarakat. Di tengah hiruk-pikuk kehidupan masyarakat, akibat pengaruh globalisasi, informasi dan trasportasi, performance (kompetensi) dan kinerja para penyuluh agama juga harus semakin ditingkatkan guna mengatasi keanekaragaman persoalan yang dialami, dirasakan dan dihadapi oleh masyarakat. Akhir-akhir ini sederet persoalan seperti persoalan kebangsaan, kebhinekaan, narkoba, korupsi, terorisme 
dan radikalisme, menjadi persoalan serius yang tengah dihadapi oleh bangsa dan negara kita. Pendekatan penyelesaiannyapun tidaklah mudah, tetapi membutuhkan pendekatan komprehensif, mulai dari sistem kebijakan yang dibangun oleh negara, regulasi sampai kepada pelibatan masyarakat. Dengan kata lain tidak bisa dilakukan secara "sektoral" tetapi partisipasi masyarakat, institusi-institusi pendidikan dan keagamaan di masyarakat, elemen-elemen masyarakat seperti lembaga-lembaga adat sangat perlu diberdayakan.

Tugas dan peran para penyuluh agama Islam, di masyarakat memegang peranan yang sangat strategis dalam upaya pembinaan pengetahuan, pemahaman, dan penanaman nilai-nilai ajaran agama kepada pemeluknya. Para penyuluh dipastikan mengetahui persis karakteristik, persoalan-persoalan dan tantangan yang sedang dialami, dirasakan dan yang akan dihadapi oleh ummatnya. Dalam upaya memaksimalkan kinerja penyuluh di tengah masyarakat, sistem rekruitmen penyuluh agama Islam perlu dievaluasi kembali oleh pemegang kebijakan (Kementerian Agama RI). Terkait dengan keberadaan penyuluh menurut Ahdiat terdapat empat aspek yang perlu ditata ulang yaitu; rasionalisasi jumlah penyuluh, penyempurnaan regulasi, peningkatan kompetensi penyuluh dan integrasi penyuluh agama di KUA. (Ahdiyat : 2017)

Mengingat tenaga penyuluh memiliki tugas strategis dalam pembangunan bangsa, terutama dalam mengawal program utama Pemerintahan Jokowi-JK dalam rangka revolusi mental sesuai dengan konsep nawa cita. Berdasarkan hasil observasi sementara peneliti, terdapat beberapa kasus yang berhubungan dengan pola rekruitmen tenaga penyuluh di Kabupaten Buton Tengah yaitu; pertama dalam aspek pemetaan latar belakang pendidikan penyuluh yang direkrut oleh Kementerian Agama Sulawesi Tenggara melalui Kementerian Agama Kabupaten Buton Tengah ditemukan beberapa penyuluh memiliki latar belakang pendidikan yang tidak beririsan dengan tugasnya sebagai penyuluh agama yaitu berlatar belakang bahasa Inggris; tenaga penyuluh tamatan STM, kedua; dari aspek basis geografis rekruitmen penyuluh tidak berbasis desa, sehingga terdapat beberapa desa yang tidak ada tenaga penyuluhnya, dan bahkan ditemukan dalam 1 desa terdapat dua orang penyuluh yang diluluskan yang kebetulan kedua penyuluh tersebut terindikasi sebagai keluarga kepala Kantor Urusan Agama. Sedangkan 
desa yang tidak ada penyululuhnya adalah peserta calon penyuluh yang terindikasi bukan keluarga kepala Kantor Urusan Agama. (Wa Murija, Wawancara 2017). Dengan terbitnya peraturan menteri agama tentang pengangkatan penyuluh non pns, berdampak pada berkurangnya penyuluh agama honorer (penyuluh madya) baik di kota maupun di pedesan. Kasus-kasus tersebut di atas memberikan dampak terhadap pola pembinaan keagamaan pada masyarakat di antaranya adalah matinya beberapa institusi taman pengajian alquran yang sudah berpengalaman melakukan pembinaan karena para Pembina TPA tersebut tidak terekrut lagi, tidak terkoordinasinya pola pembinaan agama Islam pada desa, kelurahan dan Kecamatan.

Berdasarkan kasus-kasus tersebut di atas, maka pembinaan keagamaan khususnya agama Islam mengalami hambatan, dan bahkan proses pelaksanaan pembinaan agama Islam tidak berjalan sesuai dengan harapan. Oleh karena itu, peneliti tertarik untuk melakukan pengkajian lebih mendalam tentang dampak kebijakan Kementerian Agama terhadap pola pembinaan keagamaan (agama Islam) pada masyarakat Buton Tengah Kecamatan Talaga Raya.

\section{B. Metode Penelitian}

Penelitian adalah penelitian deskriptif kualitatif. Data penelitian ini dikumpulkan melalui wawancara, observasi dan dokumentasi. Penelitian ini berupaya mendeskripsikan ; (1). sistem rekruitmen penyuluh keagamaan khususnya penyuluh agama Islam di desa-desa berdasarkan kebijakan Kementerian Agama Republik Indonesia nomor: DJ. III/432 Tahun 2016 melalui Direktur Jendral Bimbingan Masyarakat Islam, (2) untuk mendeskripsikan dampak kebijakan sistem rekruitmen tenaga penyuluh non PNS berdasarkan kebijakan Kementerian Agama Republik Indonesia nomor DJ. III/432 Tahun 2016.

\section{Hasil dan Pembahasan}

\section{C.1. Deskripsi Bimbingan dan Penyuluhan}

Kata penyuluhan merupakan ungkapan yang tidak asing lagi dalam masyarakat, apatah lagi dalam dunia pendidikan. Demikian juga dengan kata bimbingan, dimana maksud dan tujuannya pada hakikatnya adalah sama. 
Meskipun dalam pengertiannya mengandung sedikit perbedaan, namun secara definitive, pengertian bimbingan dan penyuluhan saling melengkapi sehingga kedua kata tersebut tidak dapat dipisahkan. Menurut Bimo Wagito, bimbingan (guidance) adalah bantuan atau pertolongan yang diberikan kepada individu atau kelompok dalam menghindari atau mengatasi kesulitan-kesulitan dalam kehidupan agar individu/kelompok tersebut dapat mencapai kesejahteraan. Sedangkan (Suhartin dan Simangungson : 2014) menjelaskan bahwa bimbingan adalah suatu bantuan yang diberikan kepada seseorang atau kelompok dalam menemukan kemampuan-kemampuannya dan segi-segi kehidupan masyarakat agar sukses dalam kehidupannya. Selanjutnya (Arifin : 2015), menjelaskan bahwa pelayanan bimbingan sebagai kegiatan-kegiatan yang terorganisir untuk memberikan bantuan secara sistematis kepada tersuluh dalam membuat penyesuaian diri terhadap pelbagai bentuk problema yang dihadapi.

Berdasarkan pengertian tersebut di atas maka yang dimaksud dengan bimbingan dan penyuiluhan agama adalah segala kegiatan yang dilakukan oleh seseorang dalam rangka memberikan bantuan kepada orang lain yang mengalami kesulitan-kesulitan rohani dalam lingkungan hidupnya. Bantuan tersebut dimaksudkan agar orang tersebut mampu mengatasinya sendiri karena kesadaran yang muncul dalam dirinya akibat pengaruh dari bantuan bimbingan yang diberikan. Pendampingan bimbingan dan penyluhan dilaksanakan berdasarkan perkembangan sikap dan perasaan keagamaan sesuai dengan tingkat dan situasi psikologis seseorang.

\section{C.2 Deskripsi Kebijakan}

Apakah makna kebijakan itu? Istilah kebijakan berasal dari kata "bijak", artinya selalu menggunakan pertimbangan akal budi dan hati nurani luhur. Pertimbangan akal budi berkaitan dengan kebenaran, sedangkan pertimbangan hati nurani luhur berkaitan dengan kebaikan dan keadilan. Jadi, kebijakan dapat dimaknai sebagai tindakan atau keputusan yang didasarkan pada pertimbangan akal budi dan hati nurani luhur sehingga tindakan atau keputusan dapat dipertanggungjawabkan kebenarannya (rasional) dan kebaikannya atau keadilannya (moral). 
Pengertian Kebijakan Menurut para Ahli, Kebijakan adalah suatu ucapan atau tulisan yang memberikan petunjuk umum tentang penetapan ruang lingkup yang memberi batas dan arah umum kepada seseorang untuk bergerak. Secara etimologis, kebijakan adalah terjemahan dari kata policy. Kebijakan dapat juga berarti sebagai rangkaian konsep dan asas yang menjadi garis pelaksanaan suatu pekerjaan, kepemimpinan, dan cara bertindak. Kebijakan dapat berbentuk keputusan yang dipikirkan secara matang dan hati-hati oleh pengambil keputusan puncak dan bukan kegiatan-kegiatan berulang yang rutin dan terprogram atau terkait dengan aturan-aturan keputusan.

Berdasarkan penjelasan tersebut di atas, maka kebijakan yang dimaksud dalam tulisan ini adalah kebijakan Kementerian Agama Republik Indonesia nomor DJ. III/432 Tahun 2016. yang dijadikan sebagai rujukan melakukan rekruitmen tenaga penyuluh agama Islam non PNS tahun 2016.

\section{C.3 Mekanisme Rekruitmen}

Mekanisme dan prosedur pengangkatan penyuluh agama Islam non Pegawai Negeri Sipil dilakukan oleh Kementerian agama Kabupaten Buton Tengah meliputi seluruh tahapan mulai dari pengumuman pendaftaran sampai terbitnya sk penyuluh agama Islam non pegawai negeri sipil. Proses ini dimulai dengan membentuk panitia rekruitmen penyuluh agama non Pegawai Negeri Sipil yang terdiri dari ketua, sekretaris dan anggota. Kepala Kantor kementerian agama Kabupaten Buton Tengah mengatakan pembentukan panitia rekruitmen pengangkatan penyuluh agama non Pegawai Negeri Sipil sudah berdasarkan petunjuk teknis pengangkatan penyuluh agama Islam non pegawai negeri sipil. (Adnan Sauf : 2018).

Rekruitmen penyuluh agama Islam non PNS ini bertujuan menetapkan kualifikasi dan kriteria yang digunakan dalam proses pengangkatan penyuluh agama Islam non PNS. Kualifikasi yang dimaksudkan pada pengangkatan penyuluh agama non pegawai negeri sipil berdasarkan tujuan dan fungsi kebimasIslaman yaitu ; (1) penyuluh agama buta aksara alquran, yang bertugas untuk secara bertahap menjadikan kelompok binaan dapat membaca dan 
menulis Alquran (2) Penyuluh keluarga sakinah yang bertugas untuk membentuk dan memberikan penyuluhan kepada masyarakat tentang cara mewujudkan keluarga yang sakinah, (3) Penyuluh agama bidang Zakat, yang bertugas untuk meningkatkan pendayagunaan zakat dari dan untuk masyarakat, (4) penyuluh agama bidang perwakafan, yang bertugas untuk meningkatkan potensi pendayagunaan wakaf dari dan untuk masyarakat, (5) penyuluh agama bidang prodak halal, yang bertugas menciptakan masyarakat muslim Indonesia yang sadar halal, (6) penyuluh kerukunan umat beragama yang bertugas mendorong masyarakat untuk menciptakan kerukunan dalam kehidupan beragama, (7) penyuluh radikalisme dan aliran sempalan, yang bertugas untuk membantu instansi yang berwenang dalam pencegahan tumbuhnya perilaku radikal dan aliran sempalan di masyarakat dengan pendekatan agama (8) penyuluh Napza dan HIV/AIDS, yang bertugas untuk membantu instansi berwenang dalam proses rehabilitasi pengguna napza dan ODHA dengan pendekatan spiritual (Dirjen Bimas Islam : 2017).

Oleh karena itu sebelum dilakukan ujian tertulis panitia yang ditunjuk sebagai pelaksana penerimaan penyuluh agama Islam non PNS melakukan seleksi berkas (administrasi). Semua peserta yang berasal dari Talaga Raya yang terdiri dari 16 orang pelamar dari aspek usianya telah memenuhi syarat yaitu umur serendah-rendahnya 22 tahun dan setinggi-tingginya 60 tahun. Ini dapat dibuktikan dari Kartu tanda Penduduk masing-masing pelamar yang menjadi syarat administrasi sebelum mengikuti tes tertulis (Zulaini : 2018).

Syarat yang ke dua adalah memiliki kompetensi penyuluhan agama, dalam menyeleksi syarat yang kedua panitia penyeleksi dapat melihat dari surat keterangan dari binaan penyuluhan baik dari majelis taklim maupun dari pengurus masjid/mushallah. Lebih lanjut Kepala Kantor Urusan Agama (KUA) Talaga Raya mengatakan seluruh pelamar penyuluh agama non pegawai negeri sipil yang berasal dari Talaga Raya memenuhi syarat dan memiliki surat keterangan yang dimaksud. Syarat yang ke tiga adalah sehat jasmani dan rohani. Syarat yang ketiga ini dapat dibuktikan dengan memilikinya surat keterangan sehat dari dokter atau pihak puskesmas. 
Syarat yang keempat, pelamar memiliki rekomendasi dari Pokjaluh Kabupaten/Kota. Seluruh pelamar penyuluh agama non pegawai negeri sipil yang berasal dari Kecamatan Talaga Raya memiliki rekomendasi dari Pokjaluh Kabupaten. Rekomendasi ini diterbitkan oleh Kepala kantor kementerian agama kabupaten Buton Tengah berdasarkan Surat Keputusan yang diterbitkan sebelumnya atau sebelum ada perekrutan atau pengangkatan penyuluh agama non pegawai negeri sipil. Menurut Kepala Kantor Urusan Agama Talaga Raya semua pelamar dari kecamatan Talaga Raya wajar memiliki rekomendasi dari pokjaluh kabupaten karena semua pelamar penyuluh agama non pegawai negeri sipil telah memiliki surat keputusan penyuluh agama honorer sebelum pengangkatan penyuluh agama Islam non pegawai negeri sipil tahun 2017.

Zulaini sebagai Kepala Kantor urusan agama merasa bersyukur karena semua pelamar yang berasal dari kecamatan Talaga Raya dinyatakan lulus berkas atau administrasi. Ini berarti bahwa semua pelamar calon penyuluh agama Islam non PNS memenuhi syarat administrasi baik persyaratan umum maupun persyaratan khusus. Sesuai dengan juknis dari direktur Jenderal Bimbingan Masyarakat Islam tidak sulit untuk melengkapi syarat administrasi baik yang sifatnya umum maupun persyaratan khusus.

Selain bertujuan menetapkan kualifikasi dan kriteria juga bertujuan untuk merumuskan prosedur, tahapan-tahapan pengangkatan penyuluh agama non PNS. Tahapan yang dimaksudkan dalam proses penerimaan penyuluh agama Islam non PNS adalah proses pendaftaran dimulai pada tgl 24-28 oktober 2016 yang didahului dengan pengumuman via media massa dan di tempel pada masingmasing kantor urusan agama, termasuk kantor urusan agama Talaga Raya, bagi yang jauh dari ibu kota kecamatan seperti Talaga Besar, desa Kokoe dan desa Wulu penyampaiannya melalui sms dari kepala kantor urusan agama kecamatan Talaga Raya baik kepada penyuluh agama honorer yang bersangkutan (guru-guru taman pendidikan alquran) maupun kepada kepala desa dan aparatnya. Lanjut Zulaini upaya penyampaian ini saya lakukan agar seluruh masyarakat yang mempunyai potensi dan pengalaman tentang kepenyuluhan dapat mengikuti kompetisi secara sehat. 
Tahap selanjutnya adalah tes tertulis yang dilaksanakan secara serentak di seluruh Indonesia pada hari ahad tgl 20 Nopember 2016. Ujian tertulis ini diikuti oleh seluruh peserta pelamar penyuluh agama non pegawai negeri sipil yang dinyatakan lulus dalam tahap seleksi berkas (administrasi). 16 orang pelamar penyuluh agama Islam non pegawai negeri sipil yang berasal di Talaga Raya mengikuti tes tertulis yang dilaksanakan pada Madrasah Tsanawiyah Kabupaten Buton Tengah. Peserta ujuan tertulis akan menjawab soal sebanyak 100 butir soal yang dibuat oleh kementerian agama pusat. Tes butir soal itu mencakup kompetensi keagamaan meliputi membaca dan memahami alquran, memahami ilmu Fiqh, memahami Hadist, dan memahami sejarah Nabi Muhammad Saw., dilanjutkan dengan wawancara sekaligus. Lembaran jawaban peserta ujian dikirim ke Kantor Wilayah Kementerian agama Sulawesi Tenggara untuk dilakukan pemeriksaan. Selanjutnya hasil pemeriksaan dikirim kembali ke Kabupaten Buton Tengah.

Kepala Kantor Kementerian Agama (Kemenag) Kabupaten Buton Tengah melalui Kasi Bimbingan masyarakat Islam Muchtar, S.Ag, MA mengatakan bahwa peserta yang dinyatakan lulus merupakan calon penyuluh terbaik dengan perolehan nilai akumulasi beberapa tahapan tes, baik nilai tes tertulis maupun hasil wawancara. Materi wawancara antara lain praktik, shalat jenazah, ceramah, mengaji dan lain-lain. (Muhtar : 2018).

Penyuluh agama non PNS Tahun 2017 untuk masing-masing kabupaten/kota akan ditetapkan sebanyak delapan orang pada setiap Kantor urusan Agama atau setiap kecamatan. Hal ini dilakukan dalam rangka menyasar seluruh wilayah yang belum tersentuh oleh penyuluh selama ini. Untuk wilayah tertentu jumlah tersebut akan disesuaikan jika memang butuh lebih banyak tentu ditambah seperti Kecamatan Talaga Raya yaitu 9 orang. Ke Sembilan penyuluh yang berada di kecamatan Talaga Raya yang akan di tempatkan di kecamatan dan ditugaskan di desa-desa.

Pengangkatan penyuluh agama Islam non pegawai negeri sipil tahun 2017 ditentukan melalui proses pengangkatan serangkaian tahapan seleksi yang dilakukan oleh Kantor Kementerian Agama Kabupaten/Kota. Tahapan yang dimaksudkan adalah hasil tes tertulis dari satu kecamatan diurut dari yang 
tertinggi sampai yang terendah. Peserta tes dari Kecamatan Talaga Raya di ikuti sebanyak 16 orang dan yang diangkat 9 orang. Sehingga peserta tes yang masuk rangking sembilan (9) besar dinyatakan lulus tes seleksi. Pemeriksaan dan penentuan kelulusan ini dilakukan oleh pihak Kantor wilayah Kementerian Agama Sulawesi Tenggara. Mekanisme seperti ini, lanjut Adnan Saupi tidak menimbulkan image adanya penyimpangan yang dilakukan oleh pihak kemenag tingkat kabupaten maupun tingkat kecamatan. (Adnan Saufi : 2018).

Selanjutnya panitia menyerahkan hasil seleksi dengan berita acara kepada Kepala Kementerian agama Kabupaten untuk ditetapkan pengangkatan calon penyuluh Agama non pegawai negeri sipil yang dinyatakan telah lulus seleksi untuk jangka waktu 3 (tiga) tahun.

\section{4 Dampak Kebijakan Kementerian Agama Republik Indonesia}

Lahirnya PMA Nomor 34 Tahun 2016 merupakan harapan baru bagi penyuluh dan peran KUA secara umum . Regulasi ini sudah lama ditunggu banyak pihak karena akan memperkuat tugas dan fungsi Kepala Kantor Urusan Agama di lapangan, sehingga tidak ada dualisme tugas di KUA.

Menyatunya penyuluh agama Islam, baik Pegawai negeri Sipil maupun honorer, akan memberi arah yang jelas yang dikoordinasi langsung oleh Kepala KUA. Tugas pembimbingan, pelayanan, pemberdayaan, dan pengembangan masyarakat Islam memiliki arah yang lebih kuat karena menjadi satu kesatuan tugas di tingkat KUA Kecamatan. Jika selama ini pertanggungjawaban penyuluh kepada Kemenag Kabupaten/Kota, mereka sekarang akan bertanggung jawab kepada Kepala KUA. Artinya Kepala KUA power full dalam menyusun, merencanakan, dan mengeksekusi tugas-tugas di lapangan dan tidak hanya berfokus pada tugas-tugas pernikahan. Berdasarkan mekanisme tersebut kepala Kantor Urusan Agama kecamatan Talaga Raya mengatakan tidak lagi terjadi pelaksanaan penyuluh agama, lain yang ada di sk, lain yang menjalankan tugas kepenyuluhan seperti yang terjadi tahun-tahun sebelumnya.

Seiring dengan bertambahnya tugas kepala KUA, dibutuhkan SDM yang mumpuni, yang mampu menjadi eksekutor, mediator, dan coordinator tugas lintas instansi, seperti sinergitas dengan Kantor Kecamatan, Kepolisian, termasuk 
membangun relasi dengan para tokoh agama-agama di tingkat kecamatan. Situasi tersebut, secara otomatis akan mengangkat daya tawar KUA di hadapan para tokoh local, khususnya di tingkat pimpinan daerah pada level kecamatan.

Mantan Dirjen Bimas Islam, Machasin, pernah mengusulkan agar KUA masuk dalam forum Pimpinan daerah tingkat kecamatan, selain camat, Kapolsek dan Dandim. Sebab, tidak jarang masalah yang muncul di masyarakat terkait dengan aspek agama, Konflik SARA di level grass root terkadang karena adanya gesekan paham atau keyakinan, dan itu menjadi ranah KUA.

Oleh sebab itu, bersatunya penyuluh agama di KUA diharapkan akan menjadi spirit yang menguatkan pelakasanaan tugas public. Tugas kepenyuluhan yang langsung dikoordinasi Kepala KUA diharapkan akan menambah energy dalam pelaksanaan tugas keummatan secara umum. Sehingga tidak ada lagi salah kaprah anggapan bahwa KUA hanya menjadi tempat orang menikah saja.

Apabila dievaluasi pengangkatan penyuluh agama Islam non pegawai negeri sipil dikecamatan Talaga Raya mempunyai dampak yang negative, baik dari aspek sumber daya para penyuluh, system rekruitmen tenaga penyuluh, rasionalisasi maupun kesejahteraan para penyuluh.

\section{Kinerja Para Penyuluh tidak Maksimal}

Untuk memenuhi kebutuhan penyuluh agama di kecamatan Talaga Raya sesuai dengan fungsinya, dibutuhkan sumber daya manusia yang mumpuni. Sesuai dengan visi kecamatan Talaga Raya yaitu mewujudkan kecamatan Talaga raya sebagai kawasan BERSERI (Bersih, Sejahtera, Religius) maka kehadiran penyuluh agama sangat dibutuhkan dalam rangka mewujudkan visi tersebut.

Berdasarkan teori kepenyuluhan yang diungkap oleh Asep Muhyiddin kompetensi yang harus dimiliki oleh penyuluh agama Islam adalah Memiliki wawasan keIslaman yang komprehensif, memiliki keahlian dibidang bimbingan penyuluhan. Keberadaan para penyuluh di kecamatan Talaga Raya khususnya non pegawai negeri sipil tidak memiliki kompetensi atau kemampuan yang memadai, sehingga keberadaan mereka kurang berpengaruh atau peranan penyuluh agama non pegawai negeri sipil tidak nampak, dan tidak menunjukkan adaya perbedan antara penyuluh agama honorer yang diangkat 
sebelum pengangkatan penyuluh agama Islam non pegawai negeri sipil tahun 2017. Penyebabnya adalah dilihat dari aspek pemetaan latar belakang pendidikan penyuluh agama yang direkrut oleh kementerian agama Sulawesi Tenggara melalui kementerian agama Kabupaten Buton Tengah memiliki latar belakang pendidikan yang tidak beririsan dengan tugasnya sebagai penyuluh agama. Berikut tabel daftar penyuluh agama non pegawai negeri sipil berdasarkan tingkat pendidikan dan jurusannya.

\section{Tabel 1}

Daftar Penyuluh Agama Non PNS berdasarkan Tingkat pendidikan

\begin{tabular}{llll}
\hline No & Nama Penyuluh & Tingkat Pendidikan & Ket \\
\hline 1 & Afris, S.H.I & S1 (Sarjana) & Syariah \\
\hline 2 & Barlina, A.Md & D3 & Kependidikan \\
\hline 3 & Wa Jaya & SMA & \\
\hline 4 & Zuili & SMK & Kejuruan (STM) \\
\hline 5 & Gusniah & SMA & Kependidikan \\
\hline 6 & Azmin, S.Pd & S1 & Kependidikan \\
\hline 7 & Abdul Kadir, S.Pd.I & S1 & Kependidikan \\
\hline 8 & Ode Yuniarti. S.Pd & S1 & Kependidikan \\
\hline 9 & Jumadil Ahir Nahuseng S. Pd.I & S1 & \\
\hline
\end{tabular}

Sumber Data Kantor Urusan Agama kec. Talaga Raya

Tabel tersebut menunjukkan bahwa diantara 9 tenaga penyuluh agama Islam non pegawai negeri sipil, hanya 1 orang yang memenuhi syarat utama untuk diangkat menjadi tenaga penyuluh, yaitu atas nama Afris, SH.I. Dalam petunjuk teknis pengangangkatan penyuluh agama Islam non pegawai negeri sipil pada poin 2 dikatakan pengangkatan penyuluh agama diutamakan sarjana non kependidikan. Tiga (3) orang pilihan alternative kedua sebagaimana pada poin 3 pada juknis pengangkatan penyuluh agama dikatakan dalam hal tertentu disuatu wilayah tidak terdapat Sumber Daya Manusia, dimungkinkan untuk 
mengangkat penyuluh agama non pegawai negeri sipil berpendidikan SMU/sederajat. Empat (4) orang lainnya alternative ketiga yaitu dalam hal tertentu, pengangkatan penyuluh agama Islam non pegawai negeri sipil dapat dilakukan bagi tokoh tertentu yang sudah dikenal dan diketahui kiprahnya, pengalaman serta pengabdiannya dalam bidang dakwah di tengah masyarakat yang dibuktikan dengan surat keterangan dari Majelis Ulama Indonesia (MUI) Kecamatan.

Berdasarkan kebijakan di atas menimbulkan dampak pada pelaksanaan penyuluhan keagamaan di masyarakat kecamatan Talaga Raya yaitu melaksanakan penyuluhan tidak sepenuhnya sesuai tujuan dan fungsi Bimas Islam. Untuk mengetahui tugas penyuluh agama di kecamatan Talaga Raya sesuai laporan bulanannya dapat dilihat pada tabel berdasarkan bidang garapannya :

Tabel 2.

Daftar Penyuluh Agama non PNS berdasarkan Bidang Garapan

\begin{tabular}{|c|c|c|c|}
\hline No & Nama Penyuluh & Bidang Garapan & Ket \\
\hline 1 & Azmin & Pemberantasan Buta Huruf & \\
\hline 2 & Afris, SH.I & Pemberantasan Buta Huruf & \\
\hline 3 & Zuili & Pemberantasan Buta Huruf & \\
\hline 4 & Ode Yuniarti, S.Pd & Pelaksanaan Pembinaan & \\
\hline 5 & Gusniah & Pemberantasan Buta Huruf & \\
\hline 6 & Barlina, A.Md & Pemberantasan Buta Huruf & \\
\hline 7 & Wajaya & Pemberantasan Buta Huruf & \\
\hline 8 & Abdul Kadir, S.Pd.I & Pemberantasan Buta Huruf & \\
\hline 9 & Jumadil Ahir Nahuseng, S.Pd.I & Kerukunan Umat beragama & \\
\hline
\end{tabular}

Sumber data:KUA Talaga Raya berdasarkan laporan bulanan penyuluh non PNS

Berdasarkan tabel tersebut, bahwa pengangkatan penyuluh agama Islam non pegawai negeri sipil di kecamatan Talaga Raya hanya terdapat tiga bidang 
garapan atau kulifikasi diantara 8 kualifikasi sebagai tugas BimasIslam yang ditetapkan Dirjen Bimas Islam. yaitu pemberantasan buta huruf alquran sebanyak 7 orang, kerukunan umat 1 orang dan pembinan keluarga sakinah 1 orang, Jika kita merujuk kepada tiga fungsi utama penyuluh agama adalah sebagai fungsi informative dan edukatif, konsultatif dan advokatif. Berdasarkan bidang garapan maka fungsi penyuluh agama mendominasi pemberantasan buta huruf alquran.

Sebagaimana yang berkembang di masyarakat, selama ini tugas penyuluh agama Islam adalah membimbing atau mengajar mengaji pada taman pendidikan alquran. Bahkan salah satu persyaratan untuk melamar penyuluh agama Islam non pegawai negeri sipil adalah memiliki surat keterangan dari binaan penyuluhan atau binaan taman pendidikan alquran yang ditandatangani oeh pengurus masjid atau majelis taklim. Hal ini diungkapkan oleh salah seorang penyuluh agama Islam non pegawai negeri sipil yang terekrut pada tahun 2017.

Menurut salah seorang penyuluh agama Islam non pegawai negeri sipil yang berinisial AZ menyatakan bahwa selama menjadi penyuluh agama Islam non pegawai negeri sipil di Kecamatan Talaga Raya tidak pernah melakukan ceramah apalagi melaksanakan khutbah jumat. Yang kami ketahui tugas penyuluh agama adalah mengajar mengaji pada taman pendidikan alquran, karena inilah yang kami lakukan sebelum ada pengangkatan penyuluh agama Islam non pegawai negeri sipil.

Berdasarkan hasil wawancara di atas, kementerian agama Kabupaten Buton Tengah belum melakukan sosialisasi tentang tugas dan fungsi penyuluh agama khususnya pada para penyuluh agama yang berada di kecamatan Talaga Raya.

Rendahnya insentif para penyuluh honorer membuat kinerja para penyuluh tidak maksimal. Hal ini bertentangan dengan salah satu misi kecamatan Talaga Raya yaitu memberi perlindungan dan pembinaan dalam rangka mengembangkan kualitas hidup untuk peningkatan kesejahteraan masyarakat. Seorang penyuluh agama Islam non pegawai negeri sipil yang berinisial ZL mengatakan sebenarnya tugas penyuluh itu sangat berat. Setiap bulannya kita 
melaporkan kegiatan penyuluhan dan dalam sebulan kita melaksanakan penyuluhan mulai dari hari senin sampai sabtu dengan berpenghasilan Rp. 500.000/bulan. Dengan jumlah tersebut sangat kurang bila kami membandingkan dengan teman kami yang profesinya sebagai nelayan berpenghasilan dalam sehari kadang mencapai Rp.700. 000 perhari. Walaupun insentif tenaga penyuluh agama Islam non pegawai negeri sipil telah dinaikkan dari Rp.300.000 perbulan menjadi Rp. 500.000 sejak tahun 2017, tetap saja dengan jumlah sebesar itu masih tetap rendah seiring dengan tuntutan hidup yang semakin meningkat.

\section{Mematikan Beberapa Taman Pendidikan Alquran}

Sesuai dengan misi kecamatan Talaga Raya yaitu mewujudkan kecamatan Talaga Raya sebagai kawasan BERSERI (Bersih, Sejahtera, Religius) yang berwawasan lingkungan melalui perencanaan, pengelolaan, dan pemanfaatan sumber daya alam secara arif dan bijaksana, maka kehadiran penyuluh agama non pegawai negeri sipil sangat dibutuhkan.

Kepala seksi Bimas Islam Kabupaten Buton Tengah (Muchtar : 1018) mengatakan penyuluh agama Islam non pegawai negeri sipil di tempatkan di tingkat kecamatan tapi bertugas di desa-desa. Berdasarkan pernyataan Kepala seksi Bimas Islam maka penyebaran tenaga penyuluh agama Islam non pegawai negeri sipil di Kecamatan Talaga Raya harus merata. Talaga Raya mendapatkan kuota penyuluh agama non Pegawai negeri sipil sebanyak 9 orang yang akan didistribusi ke 7 desa termasuk kelurahan. Berdasarkan kebijakan itu mengakibatkan adanya desa yang tidak memiliki penyuluh agama Islam non pegawai negeri sipil. Berikut daftar distribusi penyuluh agama Islam non pegawai negeri sipil di kecamatan Talaga Raya dan tempat penyuluhan.

\section{Tabel 3.}

Daftar Penyuluh Agama Islam non PNS berdasarkasn sebaran Tiap Desa

\begin{tabular}{cccc}
\hline No & Nama & Jumlah Penyuluh & Ket \\
\hline 1 & Talaga I & 4 orang & \\
\hline 2 & Talaga II & 1 orang \\
\hline 3 & Talaga Besar & - \\
\hline
\end{tabular}




\begin{tabular}{llc}
\hline 4 & Wulu & 1 orang \\
\hline 5 & Kokoe & 2 0rang \\
\hline 6 & Pangilia & - \\
\hline 7 & Liwu Lompona & - \\
\hline
\end{tabular}

Sumber Data: Kantor KUA berdasarkan Laporan tiap penyuluh

Berdasarkan tabel di atas penempatan penyuluh agama Islam non pegawai negeri sipil tidak terdistribusi secara merata. Diantara 7 desa yang ada di Kecamatan Talaga Raya terdapat 3 (tiga) desa yang tidak mempunyai tenaga penyuluh agama Islam non pegawai negeri sipil yaitu desa Pangilia yang mempunyai kepadatan penduduk 1195 jiwa atau 11,19\% dari jumlah penduduk kecamatan Talaga Raya, desa Liwu Lompona dihuni penduduk 1304 jiwa atau 12,22\%, dan Talaga Besar memiliki kepadatan penduduk ketiga setelah kelurahan Talaga I dan desa Talaga II dengan jumlah penduduk 1740 jiwa atau 16,28\%. Ketiga desa ini memiliki kepadatan penduduk yang sangat besar. Zulaini selaku Kepala Kantor urusan agama yang membawahi penyuluh agama mengatakan pengangkatan penyuluh agama berbasis kecamatan, dan penentuan kelulusan ditentukan dengan hasil tes, maka tidak ada jaminan setiap desa akan memiliki penyuluh agama Islam non pegawai negeri sipil, seperti apa yang terjadi di Talaga besar, Pangilia dan Liwu Lompona (Zulaini : 2018).

Kebijakan ini memberikan dampak terhadap pola pembinaan keagamaan pada masyarakat yaitu matinya beberapa institusi taman pendidikan alquran yang sudah berpengalaman melakukan pembinaan karena para Pembina Taman Pendidikan alquran tersebut tidak terekrut lagi dan tidak terkordinirnya pola pembinaan keagamaan Islam pada desa, kelurahan dan Kecamatan. Untuk melihat Taman Pendidikan Alquran mana yang masih aktif dan mana yang sudah tidak aktif lagi dapat kita lihat pada dua (2) table berikut ini. 


\section{Tabel 4.}

\section{Daftar Penyuluh Agama Islam tahun 2016 dan Jumlah Santri}

No Nama Penyuluh

Nama Jumlah Ket

\begin{tabular}{|c|c|c|c|c|c|}
\hline & & Desa/Kecamatann & /Penyuluhan & Santri & \\
\hline \multirow[t]{2}{*}{1} & Zaimar & Talaga Besar & TPQ & 27 & Aktif \\
\hline & Mukjizatin & & Babussalam & & \\
\hline 2 & Wa Murija & Talaga Besar & TPQ Al-Bahri & 31 & Aktif \\
\hline \multirow[t]{2}{*}{3} & Wa Wati & Talaga Besar & TPQ & 24 & Aktif \\
\hline & & & Muttaqin & & \\
\hline \multirow[t]{2}{*}{4} & Abdul & Kokoe & TPQ Attarbiyah & 15 & Aktif \\
\hline & S.Pd.I & & & & \\
\hline \multirow[t]{2}{*}{5} & Jumadil Ahir & Kokoe & TPQ Al-Amin & 36 & Aktif \\
\hline & Nahuseng, S.Pd.I & & & & \\
\hline \multirow[t]{2}{*}{6} & Wa Jaya & Wulu & TPQ. $\quad$ Nurul & 29 & Aktif \\
\hline & & & Hikmah & & \\
\hline 7 & Barlina, & Talaga II & TPQ Al-Qautsar & 30 & Aktif \\
\hline 8 & Afris, SH.I & Talaga I & TPQ Al-Khairat & 34 & Aktif \\
\hline 9 & Azmin, S.Pd & Talaga I & TPQ Ulul Azmi & 123 & Aktif \\
\hline 10 & Ode Yuniarti & Talaga I & MT. Khairunnisa & 34 & Aktif \\
\hline 11 & Zuili & Talaga I & TPQ Al-Huda & 33 & Aktif \\
\hline 12 & Gusniah & Talaga I & $\begin{array}{l}\text { TPQ Al- } \\
\text { Muhajirin }\end{array}$ & 28 & Aktif \\
\hline 13 & La Ipa & Pangilia & TPQ khairunnisa & 21 & Aktif \\
\hline 14 & La Sago & Panglia & $\begin{array}{ll}\text { TPQ } & \text { Asmaul } \\
\text { Husnah } & \end{array}$ & 18 & Aktif \\
\hline 15 & WD Maznia & Talaga II & $\begin{array}{ll}\text { TPQ. } & \text { Nurul } \\
\text { Huda } & \end{array}$ & 19 & Aktif \\
\hline 16 & Irdawati & Liwipompona & TPQ Al Hidayah & 25 & Aktif \\
\hline
\end{tabular}


Tabel 5.

Daftar Penyuluh Agama Non PNS tahun 2017/2018

\begin{tabular}{|c|c|c|c|c|c|}
\hline \multirow[t]{2}{*}{ No } & \multirow[t]{2}{*}{ Nama Penyuluh } & Nama & Nama & Jumlah & Ket \\
\hline & & Desa/Kecamatan & /Penyuluhan & Santri & \\
\hline \multirow[t]{2}{*}{1} & Abdul & Kokoe & TPQ Attarbiyah & 15 & \\
\hline & S.Pd.I & & & & \\
\hline \multirow[t]{2}{*}{2} & Jumadil Ahir & Kokoe & TPQ Al-Amin & 36 & \\
\hline & \multirow{2}{*}{$\begin{array}{l}\text { Wa Jaya } \\
\text { Barlina, }\end{array}$} & Wulu & TPQ. & 29 & \\
\hline 4 & & Talaga II & TPQ Al-Qautsar & 30 & \\
\hline 5 & Afris, SH.I & Talaga I & TPQ Al-Khairat & 34 & \\
\hline 6 & Azmin, S.Pd & Talaga I & TPQ Ulul Azmi & 123 & \\
\hline 7 & Ode Yuniarti & Talaga I & MT. Khairunnisa & 34 & \\
\hline 8 & Zuili & Talaga I & TPQ Al-Huda & 33 & \\
\hline 9 & Gusniah & Talaga I & $\begin{array}{l}\text { TPQ } \\
\text { Muhajirin }\end{array}$ & 28 & \\
\hline
\end{tabular}

Sumber Data KUA Kecamatan Talaga Raya

Dari kedua Tabel di atas kita dapat melihat bahwa ada 7 TPQ yang sudah tidak terekrut lagi yaitu TPQ Babussalam, TPQ Al Bahri, dan TPQ Al Muttaqin. ketiga TPQ ini berasal dari Talaga Besar. Dari tiga TPQ tersebut, Taman Pendidikan Al-Qur"an Babussalam masih aktif karena Taman Pendidikan Alquran tersebut di danai oleh desa. Kedua Taman Pendidikan Alquran yaitu Al-Bahri dan Taman Pendidikan Alquran tidak beroperasi lagi.

Dampak yang ditimbulkan dengan tidak beroperasinya kedua Taman Pendidikan Alquran tersebut adalah tidak rasionalisasi antara guru taman pendidikan Alquran dengan santri atau murid. Seperti yang dialami oleh Zaimar Mukjizatin membina santri yang tidak rasional lagi yaitu dengan menghadapi santri tujuh puluh sembilan (79) orang santri.

Sedangkan dalam pembinaan baca tulis alquran menurut Badan Kontak Pemuda Remaja Mesjid Indonesia (BKPRMI) efektivitasnya pembinaan Taman 
Pendidian Alquran adalah tidak lebih dari 6 orang santri perkelompoknya, artinya satu guru menghadapi 6 orang santri. Zaimar mukjizatin mengatakan bahwa membludaknya jumlah santri yang saya bina disebabkan tidak aktifnya lagi dua taman pendidikan alquran sehingga santri yang mereka bina sebagian datang ke taman pendidian Alquran yang saya bina. Dengan banyak santri tersebut saya sulit mengkordinir santri kami.(Zaimar Mukjizatin : 2018)

Dengan tidak adanya penyuluh agama Islam di desa Talaga Besar, kepala desa Talaga Besar menyatakan kekecewaannya karena wilayah yang dipimpinnya merupakan salah satu wilayah yang tidak memiliki tenaga penyuluh agama Islam non pegawai negeri sipil, atas kekecewaan tersebut saya memberikan insentif guru mengaji dengan mengambilkan dari dana desa. Terkait dengan kecilnya honor tenaga penyuluh, kepala desa Talaga Besar mengatakan bahwa sekecil apapun honornya penyuluh agama kami butuhkan apalagi penduduk Talaga Besar semuanya $100 \%$ beragama Islam. Kami sebagai pemerintah di desa ini tidak menginginkan kalau ada diantara warga kami yang tidak bisa membaca alquran, sebab kalau membaca saja tidak bisa apalagi kalau memahami alquran. Bukan hanya itu yang kami butuhkan, khatib pada setiap hari jumat kami sudah kewalahan antara imam desa dengan kepala desa saling bergantian.

Empat (4) Taman Pendidikan Alquran yang lainnya, Khairunnisa, Asmaul Husnah, Nurul Huda dan Al-Hidayah masing-masing dari desa Pangilia dan Liwu Lompona juga tidak aktif lagi. Sehingga Azmin, sebagai tenaga penyuluh agama Islam non pegawai negeri sipil menghadapi santri sebanyak 123 orang santri. Azmin mengatakan bahwa banyaknya santri yang kami bina berasal dari desa Pangilia dan sebagian dari desa liwulompona. Kondisi seperti ini sudah tidak rasional lagi dan mengakibatkan banyak santri yang lambat perkembangan mengajinya. Bahkan ada santri yang tidak sempat lagi kami ajar mengaji sampai pulang ke rumahnya karena keterbatasan waktu (Azmin : 2018).

Berdasarkan wawancara di atas maka pengangkatan penyuluh agama Islam non pegawai negeri sipil sangat kurang yang mengakibatkan terjadinya tidak rasionalisasi antara jumlah penyuluh agama Islam non pegawai negeri sipil dengan jumlah penduduk di kecamatan Talaga Raya yaitu 10.682 jiwa. 
Menurut teori penyuluhan sebagaimana yang diungkapkan oleh Syukriadi Sambas idealnya jumlah peserta penyuluhan adalah tidak lebih dari 20 orang perkelompoknya.

\section{Penutup}

Berdasarkan hasil analisis, dapat disimpulkan bahwa Mekanisme rekruitmen penyuluh Agama Islam non pegawai negeri sipil di kementerian agama kabupaten Buton Tengah tidak ditemukan adanya penyimpangan. Mekanisme dan prosedur pengangkatan penyuluh agama Islam non Pegawai Negeri Sipil dilakukan oleh Kementerian agama Kabupaten Buton Tengah meliputi seluruh tahapan mulai dari pengumuman pendaftaran sampai terbitnya sk penyuluh agama Islam non pegawai negeri sipil mengikuti juknis pengangkatan pengangkatan Penyuluh agama yang dikeluarkan oleh direktur jenderal Bimbingan Masyarakat Islam. Bahkan sampai penentuan kelulusan ditentukan di Kantor wilayah Kementerian Sulawesi Tenggara.

Dampak Kebijakan Kementerian Agama RI nomor DJ. III/432 Tahun 2016 tentang pola rekruitmen tenaga penyuluh agama Islam non PNS terhadap pembinaan Agama Islam pada Masyarakat Kecamatan Talaga Raya Kabupaten Buton Tengah adalah (1) Kinerja penyuluh agama tidak maksimal penyebabnya adalah penyuluh yang direkrut tidak memiliki kompetensi atau kemampuan yang memadai sehingga keberadaannya kurang berpengaruh bahkan tidak menunjukkan adanya perbedaan antara penyuluh agama yang diangkat sebelum tahun 2017. Bila dilihat dari aspek pemetaan latar belakang pendidikannya penyuluh agama yang direkrut tidak beririsan dengan tugasnya sebagai penyuluh agama. Diantara 9 tenaga penyuluh agama yang direkrut hanya 1 orang yang memiliki syarat utama yang diangkat menjadi tenaga penyuluh yaitu Afris, S.Hi. Dalam petunjuk teknis pengangangkatan penyuluh agama Islam non pegawai negeri sipil pada poin 2 dikatakan pengangkatan penyuluh agama diutamakan sarjana non kependidikan. Tiga orang pilihan alternativ kedua sebagaimana pada poin 3 pada juknis pengangkatan penyuluh agama dikatakan dalam hal tertentu disuatu wilayah tidak terdapat Sumber Daya Manusia, dimungkinkan untuk mengangkat penyuluh agama non pegawai negeri sipil berpendidikan SMU/sederajat. Empat orang 
lainnya alternative ketiga yaitu dalam hal tertentu, pengangkatan penyuluh agama Islam non pegawai negeri sipil dapat dilakukan bagi tokoh tertentu yang sudah dikenal dan diketahui kiprahnya, pengalaman serta pengabdiannya dalam bidang dakwah di tengah masyarakat yang dibuktikan dengan surat keterangan dari Majelis Ulama Indonesia (MUI) Kecamatan. Rendahnya insentif para penyuluh honorer yang membuat kinerja para penyuluh tidak maksimal. Hal ini bertentangan dengan salah satu misi kecamatan Talaga Raya yaitu memberi perlindungan dan pembinaan dalam rangka mengembangkan kualitas hidup untuk peningkatan kesejahteraan masyarakat. (2) Mematikan Beberapa Taman Pendidikan Alquran. Sebelum pengangkatan penyuluh agama tahun 2017 terdata ada 16 Taman Pendidikan Alquran yang aktif melakukan pembinaan, setelah pengangkatan 2017 ada 7 TPQ yang tidak aktif lagi membina TPQ. Dengan tidak beroperasinya TPQ yang lain maka sebagian TPQ kelebihan santri yang mengakibatkan ketidakseimbangnya antara jumlah santri dengan tenaga penyuluh agama.

\section{Referensi}

Biklen \& Bogdan, Qualitative Research for Education: an Introduction to Theories and Methods, Boston: Pearson Education, 2007.

Borg \&Gall, Educational Research: an Introduction, Boston:Pearson Education, 2003.

Creswell, John W. Research Design Pendekatan Qualitatif, Quantitatif and Mixed, ed.3 (terj), Yogyakarta: Pustaka Pelajar, 2012

Lickona, Thomas, Educating for Character How Our Schools Can Teach Respect And Responssibility, New York: Bantam Books, 1991.

Muhadjir, Noeng, Metodologi Penelitian Kualitatif, Yogyakarta: Rake Sarasin, 1996.

Muhaimin, Rekonstruksi Pendidikan Agama Islam: dari Paradigma Pengembangan, Managemen Kelembagaan, Kurikukum hingga Strategi Pembelajaran , Jakarta: PT. RajaGrafindo Persada, 2009.

Mulyasa, Managemen Pendidikan Karakter, Jakarta: PT. Bumi Aksara, 2014.

Nasution, Metode Penelitian Naturalistik-Kualitatif, Bandung: Tarsito, 2003. 
Nur Wahid, Hidayat dkk, Tim Penyusun Kurikulum Jaringan Sekolah Islam Terpadu, Jakarta: al-Hikmah, 2009.

Sugiyono, Memahami Penelitian Kualitatif, Bandung: Alfabeta, 2012.

Winarni, Sri, Integrasi Pendidikan karakter Dalam Perkuliahan, Jurnal Pendidikan Karakter, Tahun III, Nomor 1, Pebruari 2013, dikases: 21 Desember 2016. 